\title{
PENERAPAN ALGORITMA SUPPORT VECTOR MACHINE (SVM) DENGAN TF-IDF N-GRAM UNTUK TEXT CLASSIFICATION
}

\author{
Nur Arifin ${ }^{1}$, Ultach Enri ${ }^{2}$, Nina Sulistiyowati ${ }^{3}$ \\ Program Studi Teknik Informatika, Universitas Singaperbangsa Karawang ${ }^{123}$ \\ nur.arifin17013@student.unsika.ac.id ${ }^{1}$,ultach@staff.unsika.ac.id ${ }^{2}$,nina.sulistio@unsika.ac.id ${ }^{3}$
}

Submitted July 12, 2021; Revised November 26, 2021; Accepted November 26, 2021

\begin{abstract}
Abstrak
Syntax Jurnal Informatika merupakan salah satu sistem informasi yang berisikan sekumpulan artikel ilmiah yang dikelola oleh Program Studi Teknik Informatika, Universitas Singaperbangsa Karawang. Saat ini Syntax Jurnal Informatika tidak memiliki fitur untuk kategorisasi artikel ilmiah berdasarkan fokus dan ruang lingkupnya. Penelitian ini dilakukan untuk mengklasifikasi artikel ilmiah ke dalam kategori sesuai dengan fokus dan ruang lingkup yang terdapat pada laman Syntax Jurnal Informatika secara otomatis dengan memanfaatkan proses text mining. Text mining merupakan proses yang bertujuan untuk mendapatkan informasi penting dari teks. Metodologi penelitian yang digunakan adalah Knowledge Discovery Database (KDD) dengan tahapan data selection, preprocessing, transformation, modeling dan evaluation. Penelitian ini akan membandingkan klasifikasi berdasarkan judul pada artikel. Adapun algoritma yang digunakan adalah Support Vector Machine (SVM) dengan menggunakan empat kernel SVM, diantaranya adalah kernel linear, kernel polynomial, kernel sigmoid dan kernel RBF. Pembagian data menggunakan traintestsplit dibagi menjadi empat skenario yaitu 60:40, 70:30, 80:30 dan 90:10. Hasil penelitian setelah dilakukan pengujian terhadap model diukur dengan nilai Accuracy, Precision, Recall dan F-measure. Hasil terbaik adalah accuracy sebesar 70\%, precision sebesar $75 \%$, recall sebesar $69 \%$ dan $f$-measure sebesar $71 \%$ pada skenario perbandingan 90:10 dan kernel linear.
\end{abstract}

Kata Kunci : Support Vector Machine, Text Classification, TF-IDF, N-Gram

\begin{abstract}
Syntax Journal of Informatics is an information system that contains a collection of scientific articles managed by the Informatics Study Program of Singaperbangsa Karawang University. Currently, Syntax Journal of Informatics does not have a feature for categorizing scientific articles based on their focus and scope. The research is conducted to classify scientific articles into categories according to focus and scope contained on Syntax Journal of Informatics' page automatically by utilizing the text mining process. Text mining is a process that aims to get important information from the text. The method used in the research is Knowledge Discovery in Database (KDD) with stages of data selection, preprocessing, transformation, modeling and evaluation. This study will compare the classifications based on the title of the article. The algorithm used is the Support Vector Machine (SVM) using four SVM kernels, including the linear kernel, polynomial kernel, sigmoid kernel and RBF kernel. Data are divided into four scenarios by using traintestsplit, namely 60:40, 70:30, 80:30 and 90:10. The results of the study after testing the model are measured by of Accuracy, Precision, Recall and F-measure. The best results are accuracy of 70\%, precision of 75\%, recall of $69 \%$ and $f$ measure of 71\% in the 90:10 comparison scenario and linear kernel.
\end{abstract}

Keywords : Support Vector Machine, Text Classification, TF-IDF, N-Gram

\section{PENDAHULUAN}

Syntax Jurnal Informatika merupakan sebuah sistem informasi yang berisikan sekumpulan artikel ilmiah dan dikelola oleh Program Studi Teknik Informatika, Fakultas Ilmu Komputer, Universitas Singaperbangsa Karawang. Syntax Jurnal Informatika saat ini sudah memuat 95 
artikel ilmiah dan akan terus terjadi pertambahan. Berbagai macam hasil penelitian yang sudah diterbitkan pada laman Syntax Jurnal Informatika terdiri dari campuran kategori fokus dan ruang lingkup. Penelitian ini dilakukan untuk mengklasifikasi judul dari artikel ilmiah tersebut ke dalam kategori sesuai dengan fokus dan ruang lingkupnya secara otomatis dengan memanfaatkan proses text mining.

Text mining merupakan salah satu ilmu pencabangan data mining, Text mining merupakan sebuah proses yang memiliki tujuan untuk mendapatkan informasi penting dari suatu teks. Informasi penting tersebut umumnya dapat diperoleh dengan memperhatikan pola dan tren yang dipelajari dari pola statistik. Pola text mining tersebut terdapat pembobotan kata yang memiliki tujuan yaitu memberikan nilai atau bobot pada term yang ada pada dokumen tersebut [1].

Dalam penelitian lain menyebutkan bahwa algoritma Support Vector Machine (SVM) memiliki nilai akurasi terbaik [2]. Algoritma Support Vector Machine (SVM) adalah salah satu metode regresi atau klasifikasi data berdasarkan data sebelumnya dan modelnya dilakukan supervisi terlebih dahulu [3]. Support Vector Machine (SVM) merupakan sebuah metode yang membandingkan suatu seleksi parameter standar nilai diskrit yang disebut kandidat set [4]. Support Vector Machine (SVM) umumnya digunakan untuk binary classifier yang melakukan klasifikasi dengan membagi data menjadi 2 class yaitu dengan menggunakan hyperplane. Untuk memaksimalkan ruang antar kelas, ruang input asli diubah menjadi ruang yang berdimensi sangat tinggi disebut ruang fitur. Kernel digunakan untuk mentransformasi data ke ruang dimensi yang lebih tinggi, dan disebut ruang kernel, berguna untuk memisahkan data secara linear [5].
Data yang diambil berupa teks yaitu data judul dari situs Syntax Jurnal Informatika dan diolah menggunakan metode Knowledge Discovery Database (KDD). Knowledge Discovery Database (KDD) merupakan salah satu metode yang sering digunakan dalam text mining [6]. Tahapan Knowledge Discovery Database (KDD) yang pertama adalah data selection, kemudian preprocessing, dan transformation untuk meningkatkan hasil klasifikasi yang lebih akurat. Setelah dilakukan preprocessing data akan dilatih dan diuji dengan beberapa kernel yang ada pada algoritma Support Vector Machine (SVM) lalu tahapan ter akhir adalah evaluation.

Pada tahapan transformasi, N-Gram diterapkan dengan melakukan modifikasi pemisahan atau pemecahan berdasarkan kata. Referensi [7] menjelaskan bahwa NGram adalah suatu potongan n-karakter yang didapatkan dari suatu string. Metode N-Gram ini biasanya diaplikasikan untuk pembangkitan kata atau karakter. Untuk memudahkan perhitungan dan menghindari kesalahan pada ekstraksi Term Frequency Inverse Document Frequency (TF-IDF), maka perlu digunakannya N-Gram. Penggunaan N-Gram juga dapat memberikan keuntungan karena hasil yang diperoleh menjadi lebih akurat dan efektif [8].

Berdasarkan penelitian Liani yang berjudul "Analisis Perbandingan Kernel Algoritma Support Vector Machine dalam Mengklasifikasikan Skripsi Teknik Informatika Berdasarkan Abstrak" didapatkan menggunakan algoritma Support Vector Machine (SVM) dengan default parameter dan 4 kernel yaitu Linear, Polynomial, Radial Basis Function (RBF) dan Sigmoid menghasilkan akurasi yang cukup tinggi [9], sehingga pada penelitian ini akan menggunakan kernel yang sama yaitu kernel Linear, Sigmoid, Polynomial dan Radial Basis Function 
(RBF). Pengujian pada penelitian ini akan dilakukan untuk mencari nilai recall, precision, dan f-measure untuk menghitung nilai akurasi ketepatan klasifikasi kategori artikel ilmiah terhadap fokus dan ruang lingkupnya.

\section{METODE PENELITIAN}

Metodologi yang digunakan adalah Knowledge Discovery in Database (KDD). Knowledge Discovery in Database (KDD) merupakan salah satu metode yang sering digunakan dalam text mining. Knowledge Discovery in Database (KDD) merupakan proses kegiatan yang meliputi pengumpulan data, pemakaian data, historis untuk menemukan keteraturan, pola atau hubungan dalam set data yang memiliki ukuran besar [6]. Tahapannya dapat dilihat pada Gambar 1.

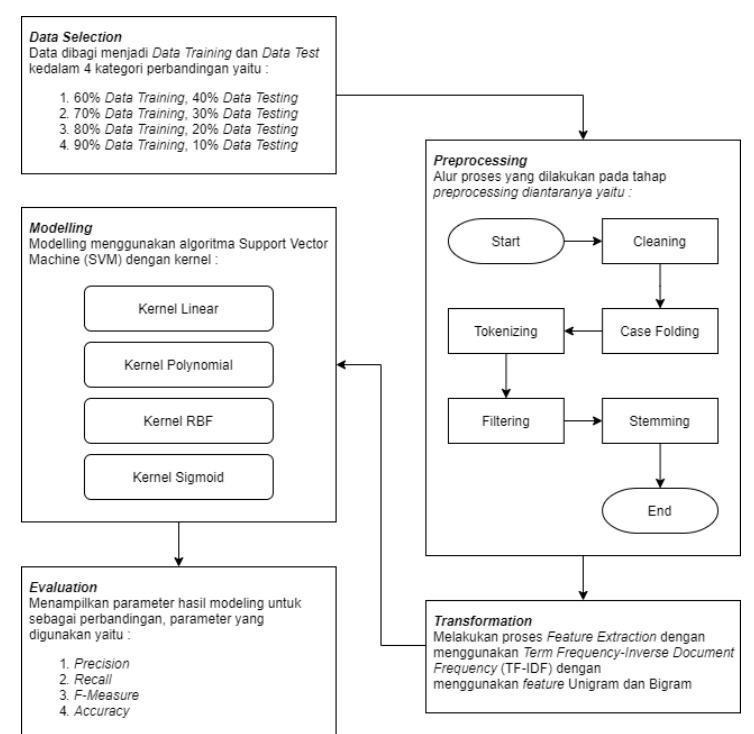

Gambar 1. Rancangan Penelitian

Dari Gambar 1, diketahui tahap penelitian yang dilakukan adalah sebagai berikut :

\section{Data Selection}

Penelitian ini menggunakan set data berupa judul artikel ilmiah yang terdapat pada laman Syntax Jurnal Informatika sebanyak 95 data. Pada tahap data selection, judul artikel ilmiah yang sudah dikumpulkan dibagi menjadi 2 set data, yaitu set data training dan set data testing. Pembagian data menggunakan Split Data dengan rasio perbandingan data training dan data testing sebesar 60:40, 70:30, 80:20 dan 90:10.

\section{Preprocesing}

Pengolahan data pada tahapan preprocessing yang diharapkan dapat meningkatkan hasil pengukuran yang baik pada tahap evaluation nanti. Adapun tahapan preprocessing sebagai berikut:

\section{Data Cleaning}

Pada tahap data cleaning, setiap kalimat yang mengandung noise yang berupa tautan situs, simbol seperti !,@,\#,\$,\%,^,\&,*,(,),/,’,[,. dan simbol lainnya atau angka akan dihapus.

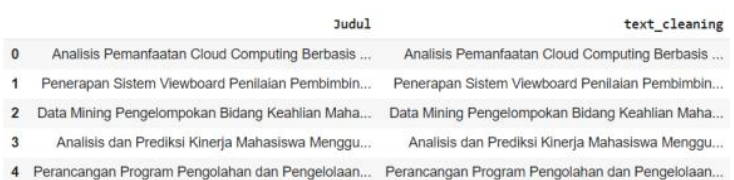

\section{Gambar 2. Hasil Proses Data Cleaning}

\section{Case Folding}

Pada tahap case folding, setiap huruf diubah menjadi huruf kecil, karena model yang dibangun bersifat case sensitif, sedangkan penggunaan huruf kapital bisa jadi tidak konsisten pada semua kata.

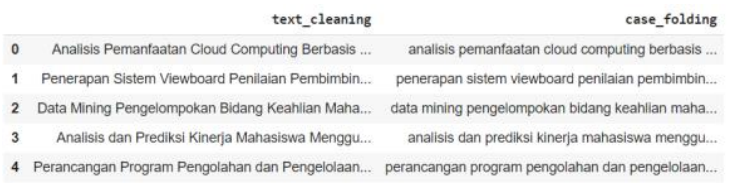

\section{Gambar 3. Hasil Proses Case Folding}

\section{Tokenizing}

Tahapan tokenizing dilakukan untuk memecah kalimat menjadi kata berdasarkan spasi. Tokenizing akan digunakan untuk tahap selanjutnya yaitu filtering dan stemming. 


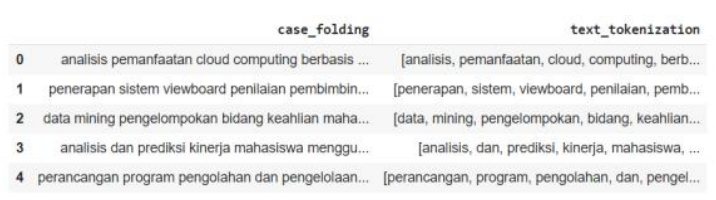

Gambar 4. Hasil Proses Tokenizing

\section{Filtering}

Filtering dilakukan untuk menghapus kata sambung seperti "dan", "atau", "yang" atau kata-kata yang kurang berpengaruh pada penelitian.

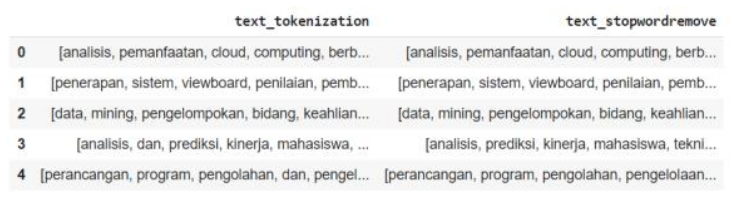

Gambar 5. Hasil Proses Filtering

\section{Stemming}

Stemming digunakan untuk mengubah seluruh kata menjadi kata dasarnya, salah satunya adalah menghapus imbuhan.

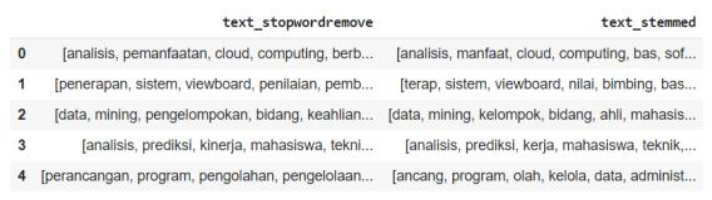

Gambar 6. Hasil Proses Stemming

\section{Transformation}

Proses transformasi bertujuan untuk mendapatkan representasi dokumen sesuai dengan yang diharapkan. Proses ini dilakukan untuk mengubah data menjadi vektor agar data mudah untuk dilakukan proses data mining. Menurut Fitri pada Referensi [5], Pembobotan Term Frequency Inverse Document Frequency (TF-IDF) adalah metode yang umumnya dipakai untuk menentukan hubungan kata (term) terhadap dokumen atau kalimat dengan memberikan bobot atau nilai pada masing-masing kata. Metode Term Frequency Inverse Document Frequency (TF-IDF) menggabungkan konsep Frequency Inverse sebuah kata di dalam sebuah dokumen dan Inverse Document Frequency yang mengandung kata tersebut. Perhitungan bobot menggunakan
Term Frequency Inverse Document Frequency (TF-IDF) yaitu dilakukan perhitungan terlebih dahulu nilai TF per kata dengan bobot masing-masing kata. Adapun perhitungan Term Frequency Inverse Document Frequency (TF-IDF) seperti yang dijelaskan pada persamaan berikut:

1. Nilai Term Frequency (TF) diperoleh dari nilai frekuensi kemunculan fitur $t$ pada dokumen $d$.

$$
T F_{t}=(t, d)
$$

2. Nilai Inverse Document Frequency diperoleh dari logaritma banyaknya dokumen $n$ dibagi dokumen $d f$ yang mengandung fitur $t$.

$$
I D F_{t}=\log \frac{n}{d f(t)}+1
$$

3. Nilai Term Frequency Inverse Document Frequency $\left(W_{t}\right)$ didapatkan dengan mengalihkan nilai $T F$ dengan IDF.

$$
W_{t}=T F_{t} \times I D F_{t}
$$

Pada proses transformasi, fitur N-Gram digunakan dengan menerapkan modifikasi pemisahan atau pemecahan kalimat menjadi kata. Referensi [8] menjelaskan bahwa N-Gram adalah suatu potongan $\mathrm{n}$ karakter yang didapatkan dari suatu string. Metode N-Gram ini biasanya diaplikasikan untuk pembangkitan kata atau karakter [7].

Beberapa kali pengujian dilakukan untuk mendapatkan akurasi terbaik, diantaranya adalah pengujian yang dilakukan untuk mendapatkan kata yang digunakan pada proses transformation dengan menentukan jumlah minimal dokumen yang memiliki kata tersebut. Nilai minimal tersebut diuji dengan 3 pengujian yaitu 1, 2 dan 3 dengan menghasilkan akurasi seperti yang ditunjukkan pada Tabel 1. 
Tabel 1. Perbandingan Jumlah Minimal Kata terhadap Akurasi

\begin{tabular}{cc}
\hline Minimal Kata & Akurasi \\
\hline 1 & $20 \%$ \\
2 & $60 \%$ \\
3 & $30 \%$ \\
\hline
\end{tabular}

Selain itu dilakukan pula pengujian menggunakan fitur $\mathrm{N}$-Gram pada proses transformation. Perbandingan perbedaan akurasi dengan menggunakan fitur $\mathrm{N}$ Gram dengan Unigram, Unigram + Bigram, dan Bigram pada Skenario dan kernel terbaik dipaparkan pada Tabel 2.

Tabel 2. Perbandingan Fitur N-Gram terhadap Akurasi

\begin{tabular}{cc}
\hline Fitur N-Gram & Akurasi \\
\hline Unigram & $60 \%$ \\
Unigram + Bigram & $70 \%$ \\
Bigram & $60 \%$ \\
\hline
\end{tabular}

Dari percobaan tersebut menghasilkan kesimpulan yaitu. Dan menerapkan fitur Unigram dan Bigram mampu meningkatkan nilai akurasi. Hasil dari dilakukannya proses TF-IDF dapat dilihat pada Gambar 7.

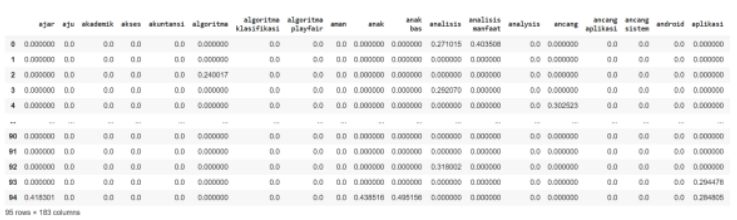

\section{Gambar 7. Hasil proses transformation dengan TF-IDF dan fitur N-Gram}

\section{Modeling}

Pada tahap modeling, data terpilih dilakukan proses untuk didapatkan informasi yang menarik dengan menggunakan algoritma tertentu. Pemilihan algoritma yang tepat sangat menentukan tujuan dan proses dari metodologi penelitian secara keseluruhan. Algoritma Support Vector Machine (SVM) masih memiliki kekurangan, secara teoritis algoritma Support Vector Machine (SVM) dikembangkan untuk masalah klasifikasi data dengan dua class, untuk mengatasi hal ini perlu digunakan teknik tambahan yang disebut dengan Kernel. Adapun kernel yang digunakan dalam penelitian ini yaitu kernel Linear, Polynomial, RBF dan Sigmoid. Berikut persamaan empat kernel SVM :

\section{Linear}

Fungsi kernel Linear merupakan fungsi kernel yang paling sederhana yaitu perkalian titik dua vektor.

$$
K\left(x_{i}, x_{j}\right)=X_{i}^{T} X_{j}
$$

\section{Polynomial}

Fungsi kernel Polynomial merupakan fungsi kernel yang memiliki derajat $d$, dimana $\mathrm{d}$ dan $\mathrm{r}$ merupakan parameter yang didefinisikan.

$$
K\left(x_{i}, x_{j}\right)=\left(\gamma \cdot X_{i}^{T} X_{j}+r\right)^{d}, \gamma>0
$$

\section{Radial Basis Function (RBF)}

Fungsi kernel Radial Basis Function (RBF) biasa disebut juga sebagai fungsi kernel Gaussian. Dimana $\gamma$ merupakan parameter untuk mengatur jarak.

$$
K\left(x_{i}, x_{j}\right)=\exp \left(-\gamma\left|X_{i}^{T} X_{j}\right|^{2}\right), \quad \gamma>0
$$

\section{Sigmoid}

Pada fungsi kernel Sigmoid, dimana tanh

$$
\begin{array}{r}
(a)=2 \sigma(a)-1 \text { dan }(a)=\frac{1}{(1+\exp (a)} . \\
K\left(x_{i}, x_{j}\right)=\tanh \left(\gamma \cdot X_{i}^{T} X_{j}+r\right)
\end{array}
$$

Kernel dibutuhkan untuk membuat dimensi baru sehingga dapat memberi batas dengan membuat hyperplane-nya, Hyperplane yang baik merupakan hyperplane yang terletak di tengah-tengah antara dua objek dari dua kelas atau dengan kata lain ekuivalen dengan memaksimalkan margin atau jarak antara kedua sel objek dari kelas yang berbeda. Untuk melakukan klasifikasi dengan algoritma Support Vector Machine (SVM) terdapat beberapa tahapan diantaranya yaitu :

1. Menentukan hyperplane atau garis pembatas antara dua support vector.

2. Menentukan margin atau garis jarak antara support vector dan hyperplane. 
3. Pemetaan support vector ke dalam suatu kelas dalam class dimensi yang sama.

\section{Evaluation}

Evaluation merupakan tahap akhir dari proses Knowledge Discovery in Database (KDD), evaluasi ini dilakukan untuk menampilkan pengetahuan agar mudah dibaca dan dipahami maka diperlukan penyajian yang menarik. Hasil penelitian yang dilakukan perlu ada pengujian dan evaluasi untuk mengetahui tingkat akurasi dan ketepatan dari hasil klasifikasi. Metode pengujian data mining yang paling banyak digunakan adalah mencari nilai precision, recall, f-measure dan accuracy [10] Nilainilai yang dicari pada tahap evaluasi diantaranya adalah :

\section{Precision}

Precision adalah hasil perbandingan dari jumlah data bernilai positif dengan hasil jumlah data benar bernilai positif dan data salah bernilai positif [1].

$$
\text { Precision }=\frac{T P}{T P+F P}
$$

\section{Recall}

Recall ialah hasil dari perbandingan nilai data benar bernilai positif dengan hasil jumlah data benar yang bernilai positif dan data salah bernilai negatif [1]

$$
\text { Recall }=\frac{T P}{T P+F N}
$$

\section{F-measure}

F-measure adalah parameter ukuran keberhasilan retrieval yang menggabungkan precision dan recall. Nilai tersebut didapat dari perhitungan perkalian nilai precision dan recall yang kemudian dibagi dengan hasil penjumlahan precision dan recall dan dikalikan dua [1]

$$
\text { F-Measure }=\frac{\text { Precision } * \text { Recall }}{\text { Precision }+ \text { Recall }}
$$

\section{Accuracy}

Accuracy digunakan untuk mengukur akurasi dari masing-masing kernel.
Dimana semakin besar nilai akurasi maka kernel yang digunakan semakin bagus [1]

$$
\text { Accuracy }=\frac{T P+T N}{T P+T N+F P+F N}
$$

\section{HASIL DAN PEMBAHASAN}

Hasil yang diperoleh dari seluruh pengujian akan dibandingkan untuk mengetahui model mana yang terbaik dalam proses pengklasifikasian. Pada Tabel 3 dipaparkan hasil perbandingan evaluasi dari setiap skenario.

Tabel 3. Hasil Perbandingan Evaluasi Model

\begin{tabular}{cccccc}
\hline $\begin{array}{c}\text { Skenario/ } \\
\text { Pembagian }\end{array}$ & Kernel & $\begin{array}{c}\text { Accu } \\
\text { racy }\end{array}$ & $\begin{array}{c}\text { Preci } \\
\text { sion }\end{array}$ & $\begin{array}{c}\text { Reca } \\
\boldsymbol{l l}\end{array}$ & $\begin{array}{c}\text { F- } \\
\text { Meas } \\
\text { ure }\end{array}$ \\
\hline 1/60:40 & Linear & $39 \%$ & $33 \%$ & $34 \%$ & $33 \%$ \\
& Sigmod & $34 \%$ & $26 \%$ & $21 \%$ & $20 \%$ \\
& Polynomial & $11 \%$ & $18 \%$ & $15 \%$ & $10 \%$ \\
& RBF & $31 \%$ & $2 \%$ & $8 \%$ & $4 \%$ \\
$2 / 70: 30$ & Linear & $55 \%$ & $51 \%$ & $52 \%$ & $50 \%$ \\
& Sigmod & $34 \%$ & $22 \%$ & $21 \%$ & $20 \%$ \\
& Polynomial & $14 \%$ & $12 \%$ & $13 \%$ & $8 \%$ \\
$3 / 80: 20$ & RBF & $31 \%$ & $2 \%$ & $8 \%$ & $4 \%$ \\
& Linear & $53 \%$ & $44 \%$ & $43 \%$ & $42 \%$ \\
& Sigmod & $32 \%$ & $16 \%$ & $20 \%$ & $17 \%$ \\
& Polynomial & $21 \%$ & $6 \%$ & $14 \%$ & $6 \%$ \\
& RBF & $32 \%$ & $3 \%$ & $10 \%$ & $5 \%$ \\
& Linear & $70 \%$ & $75 \%$ & $69 \%$ & $71 \%$ \\
& Sigmod & $40 \%$ & $34 \%$ & $38 \%$ & $35 \%$ \\
& Polynomial & $14 \%$ & $12 \%$ & $13 \%$ & $8 \%$ \\
& RBF & $20 \%$ & $3 \%$ & $14 \%$ & $5 \%$ \\
\hline
\end{tabular}

Dari Tabel 3 dapat diketahui hasil akurasi menggunakan Skenario 4 dengan pembagian 90:10, kernel linear menghasilkan nilai akurasi paling tinggi sebesar $70 \%$, precision sebesar $75 \%$, recall sebesar $69 \%$ dan $f$-measure sebesar $71 \%$. Sedangkan untuk nilai akurasi terkecil terdapat pada proses dengan Skenario 1, perbandingan 60:40 dan kernel polynomial sebesar $11 \%$, precision sebesar $18 \%$, recall sebesar $15 \%$ dan $f$-measure sebesar $10 \%$. Adapun contoh hasil prediksi dari klasifikasi menggunakan Skenario 4 dengan pembagian 90:10 dan kernel linear dapat dilihat pada Gambar 8 . 


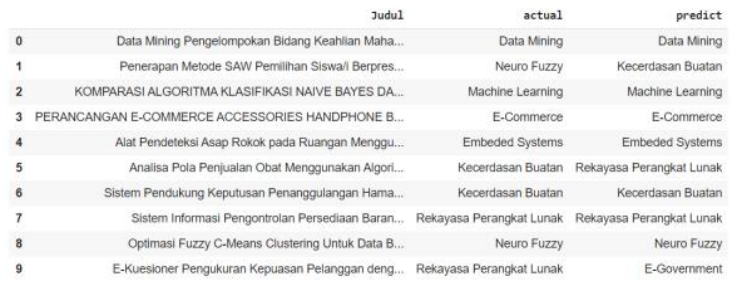

Gambar 8. Hasil Prediksi Model yang Menghasilkan Akurasi Terbaik

Dari contoh hasil prediksi yang ditampilkan pada Gambar 8, terdapat beberapa Judul mendapatkan hasil prediksi yang akurat, namun tentu saja masih terdapat beberapa perbedaan antara kategori yang diharapkan atau actual dengan kategori yang diprediksikan oleh model atau predict.

\section{SIMPULAN}

Berdasarkan penelitian yang telah dilakukan dapat ditarik beberapa kesimpulan diantaranya yaitu :

1. Text mining dan algoritma Support Vector Machine (SVM) dapat digunakan untuk proses klasifikasi pada artikel ilmiah Syntax Jurnal Informatika,

2. Penentuan jumlah minimal kata yang diproses dan fitur N-Gram berupa Unigram dan Bigram pada tahapan transformation dengan Term Frequency Inverse Document Frequency (TF-IDF), dinilai mampu meningkatkan nilai akurasi pada proses klasifikasi artikel ilmiah Syntax Jurnal Informatika. Nilai akurasi semula yaitu $30 \%$ dengan menentukan jumlah minimal kata yang diproses naik menjadi $60 \%$ dan dengan menerapkan fitur Unigram dan Bigram nilai akurasi berubah menjadi $70 \%$,

3. Data yang diolah yaitu data Judul pada Syntax Jurnal Informatika menghasilkan nilai performa terbaik terdapat pada kernel linear dengan dan Skenario pembagian data 4 yaitu 90:10 serta dengan menerapkan modifikasi pada pembobotan TF-IDF yaitu menerapkan TF-IDF Unigram dan TFIDF Bigram. Kernel linear memiliki nilai akurasi terbaik sebesar $70 \%$, recall sebesar $75 \%$, precision sebesar $69 \%$ dan $f$-measure sebesar $71 \%$. Untuk kernel sigmoid memiliki nilai akurasi terbaik sebesar 34\%, precision sebesar 26\%, recall sebesar $21 \%$ dan $f$-measure sebesar $20 \%$. Untuk kernel polynomial memiliki nilai akurasi terbaik sebesar $32 \%$, precision sebesar $3 \%$, recall sebesar $10 \%$ dan $\mathrm{f}$ measure sebesar 5\%. Dan untuk kernel RBF memiliki nilai akurasi terbaik sebesar 32\%, precision sebesar 3\%, recall sebesar $10 \%$ dan f-measure sebesar 5\%,

4. Dari hasil pengujian terbukti kernel pada algoritma Support Vector Machine (SVM) yang memiliki nilai performa terbaik antara keempatnya adalah kernel linear dengan skenario 4, pembagian 90:10 yang memiliki nilai accuracy sebesar $70 \%$, recall sebesar $75 \%$, precision sebesar $69 \%$ dan $f$-measure sebesar $71 \%$.

\section{DAFTAR PUSTAKA}

[1] W. Anggraini, M. Utami, J. Berlianty, and E. Sellya, "Klasifikasi Sentimen Masyarakat Terhadap Kebijakan Kartu Prakerja di Indonesia," Faktor Exacta, vol. 13, no. 4, pp. 255-261, 2021, doi: 10.30998/faktorexacta.v13i4.7964.

[2] A. Deolika, K. Kusrini, and E. T. Luthfi, "Analisis Pembobotan Kata Pada Klasifikasi Text Mining," Jurnal Teknologi Informasi, vol. 3, no. 2, p. 179, 2019, doi: 10.36294/jurti.v3i2.1077.

[3] V. Gupta and G. S. Lehal, "A survey of text mining techniques and applications," Journal of Emerging Technologies in Web Intelligence, 
vol. 1, no. 1, pp. 60-76, 2009, doi: 10.4304/jetwi.1.1.60-76.

[4] J. Han, M. Kamber, and J. Pei, Data Mining Concepts and Techniques. 2012. doi: 10.1016/b978-0-12381479-1.00001-0.

[5] B. Herwijayanti, D. E. Ratnawati, and L. Muflikhah, "Klasifikasi Berita Online dengan menggunakan Pembobotan TF-IDF dan Cosine Similarity," Pengembangan Teknologi Informasi dan Ilmu Komputer, vol. 2, no. 1, pp. 306312, 2018.

[6] A. Liani, U. Enri, and Y. Umaidah, "Analisis Perbandingan Kernel Algoritma Support Vector Machine dalam Mengklasifikasikan Skripsi Teknik Informatika berdasarkan Abstrak," JOINS (Journal of Information System), vol. 5, no. 2, pp. 240-249, 2020, doi: 10.33633/joins.v5i2.3715.

[7] S. Mardianti, M. Zidny, and I. Hidayatulloh, "Ekstraksi tf-Idf $n$ gram dari komentar pelanggan produk smartphone pada website ecommerce," Seminar Nasional Teknologi Informasi dan
Multimedia, vol. 6, no. , pp. 79-84, 2018.

[8] A. A. Prasanti, M. A. Fauzi, and M. T. Furqon, "Klasifikasi Teks Pengaduan Pada Sambat Online Menggunakan Metode N- Gram dan Neighbor Weighted K-Nearest Neighbor ( NW-KNN )," Pengembangan Teknologi Informasi dan Ilmu Komputer, vol. 2, no. 2, pp. 594-601, 2018.

[9] I. Riadi, R. Umar, and F. D. Aini, "Analisis Perbandingan Detection Traffic Anomaly Dengan Metode Naive Bayes Dan Support Vector Machine (Svm)," ILKOM Jurnal Ilmiah, vol. 11, no. 1, pp. 17-24, 2019 , doi: 10.33096/ilkom.v11i1.361.17-24.

[10] O. Rahman, G. Abdillah, and A. Komarudin, "Klasifikasi Ujaran Kebencian pada Media Sosial Twitter Menggunakan Support Vector Machine," Jurnal RESTI (Rekayasa Sistem dan Teknologi Informasi), vol. 5, no. 1, pp. 17-23, 2021, doi: 10.29207/resti.v5i1.2700. 